\title{
Physiotherapy practice patterns in Intensive Care Units of Nepal: A multicenter survey
}

\author{
Sumana Baidya1, Ranjeeta S. Acharya ${ }^{1}$, Michel W. Coppieters ${ }^{1,2,3}$
}

Context: As physiotherapy (PT) is a young profession in Nepal, there is a dearth of insight into the common practices of physiotherapists in critical care. Aims: To identify the availability of PT services in Intensive Care Units (ICUs) and articulate the common practices by physiotherapists in ICUs of Nepal. Settings and Design: All tertiary care hospitals across Nepal with ICU facility via an exploratory cross-sectional survey. Subjects and Methods: An existing questionnaire was distributed to all the physiotherapists currently working in ICUs of Nepal with 2 years of experience. The survey was sent via E-mail or given in person to 86 physiotherapists. Statistical Analysis Used: Descriptive and inferential statistics according to nature of data. Results: The response rate was $60 \%$ $(n=52)$. In the majority of hospitals $(68 \%)$, PT service was provided only after a physician consultation, and few hospitals (13\%) had established hospital criteria for PT in ICUs. Private hospitals (57.I\%) were providing PT service in weekends compared to government hospitals $(32.1 \%)(P=0.17)$. The likelihood of routine PT involvement varied significantly with the clinical scenarios (highest $71.2 \%$ status cerebrovascular accident, lowest 3.8\% myocardial infarction, $P<0.00 \mathrm{I})$. The most preferred PT treatment was chest PT $(53.8 \%)$ and positioning $(21.2 \%)$ while least preferred was therapeutic exercise (3.8\%) irrespective of clinical scenarios. Conclusions: There is a lack of regular PT service during weekends in ICUs of Nepal. Most of the cases are treated by physiotherapists only after physician's referral. The preferred intervention seems to be limited only to chest PT and physiotherapists are not practicing therapeutic exercise and functional mobility training to a great extent.

Keywords: Intensive Care Units, multicenter survey, Nepal, physiotherapy

\section{Introduction}

Physiotherapists in the Intensive Care Units (ICUs) are an integral part of the multidisciplinary team involved in the treatment of critically ill patients. ${ }^{[1,2]}$ Physiotherapists liaise closely with medical, nursing, and other allied health professionals regarding patient condition, progression, and treatment plans. Decade to decade, there has been a strong campaign to evaluate the level of evidence of many interventions in medicine

\section{From:}

'Department of Physiotherapy, Dhulikhel Hospital, Kathmandu University School of Medical Sciences, Dhulikhel, Kavre, Nepal, ${ }^{2}$ Department of Movement Sciences, MOVE Research Institute Amsterdam, Faculty of Behavioural and Movement Sciences, Vrije Universiteit Amsterdam, Amsterdam, The Netherlands, ${ }^{3}$ Department of Physiotherapy, School of Health and Rehabilitation Sciences, The University of Queensland, Brisbane, Australia

\section{Correspondence:}

Prof. Sumana Baidya, Department of Physiotherapy, Kathmandu University School of Medical Sciences, Dhulikhel, Kavre, Nepal.

E-mail: Sumana.baidya.pt@gmail.com

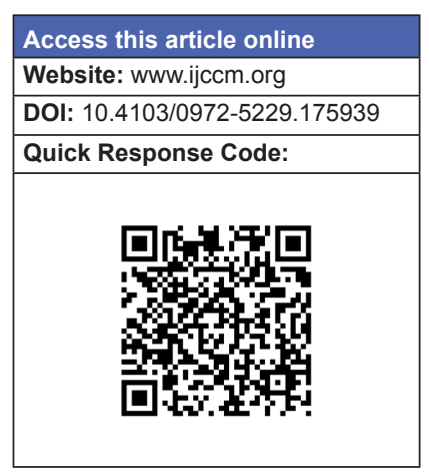

and allied health, including physiotherapy (PT). This has resulted in a large volume of randomized clinical trials, systematic reviews, and evidence-based clinical practice guidelines for PT management of common conditions. ${ }^{[3]}$

With respect to PT management of patients, a plethora of treatment modalities is suggested for most conditions

This is an open access article distributed under the terms of the Creative Commons Attribution-NonCommercial-ShareAlike 3.0 License, which allows others to remix, tweak, and build upon the work non-commercially, as long as the author is credited and the new creations are licensed under the identical terms.

For reprints contact: reprints@medknow.com

How to cite this article: Baidya S, Acharya RS, Coppieters MW. Physiotherapy practice patterns in Intensive Care Units of Nepal: A multicenter survey. Indian J Crit Care Med 2016;20:84-90. 
treated by physiotherapists. Chest PT is one of the most frequently performed interventions in the intensive care areas. ${ }^{[4]}$ The role of physiotherapists in ICU, as stated by Stiller, is positioning, percussion, vibration, manual hyperinflation, coughing, tracheal suctioning, and breathing and limb exercises..$^{[5]}$ The benefits of early mobilization include reductions in length of stay in the ICU and hospital, as well as improvements in strength and functional status. ${ }^{[6]}$ Early PT led rehabilitation of the critically ill patient has the potential to dramatically influence recovery and functional outcomes in this vulnerable patient group. ${ }^{[7]}$ In the USA, PT is most commonly and widely administered in ICU patients during recovery from critical illness. ${ }^{[8]}$ Practical guidelines for the implementation of early mobilization in ICU have been recently published, which suggest that PT management in ICU has dramatically decreased the mortality in the past decades. ${ }^{[9,10]}$

PT workforce surveys are periodically conducted in many countries. These workforce surveys document the number of physiotherapists per population, level of education, origin of training (domestic or international), domain of practice, clinical setting, employment opportunities, and trends in the workforce (e.g., change in number of therapists per population, level of specialization, etc.). Although the introduction of PT in many developing countries such as Nepal may be recent, the actual practice of PT has a long history in many other countries. ${ }^{[1]]}$ Hence, till date, there is no workforce data about PT practice in Nepal.

To date, there are no studies on how physiotherapists are involved in ICU and how they manage the common conditions in ICU in Nepal. Therefore, this study aimed to explore the involvement of PT management and therapeutic interventions provided by the physiotherapists in ICUs in Nepal. The objectives of the study were to determine the involvement of physiotherapists in weekdays versus weekend, the hours spent in ICU per day, and the involvement of physiotherapist according to the clinical scenarios. The study was also designed to ascertain the treatment skills commonly administered by physiotherapists.

\section{Subjects and Methods}

\section{Study design}

Exploratory cross-sectional survey.

\section{Participants}

Physiotherapists who are currently working in ICU with minimum 2 years of working experience in acute care hospital after graduation were requested to fill the questionnaire.

\section{Procedure}

Ethical clearance was obtained from Institutional Review Committee, Kathmandu University School of Medical Sciences, Nepal. The lists of hospitals were obtained from Ministry of Health, Government of Nepal. Each hospital with ICUs was contacted to identify the physiotherapists working in the ICU. A total of 86 physiotherapists, who met the inclusion criteria, were identified.

The survey was conducted by using the questionnaire developed by Hodgin et al. ${ }^{[8]}$ Reliability analysis was calculated for the entire survey by Cronbach's alpha (0.843) ${ }^{[8]}$ The questionnaire was sent electronically via E-mail, or alternatively, questionnaires were also delivered in person. The E-mail addresses were obtained from various sources such as professional networks, phoning each hospital, and Ministry of Health database. A covering letter was included explaining the purpose of the study, identifying the researcher, and assuring confidentiality of the respondents. If response was not obtained within the stipulated time period, two subsequent reminders via E-mail or telephone call were sent with a time gap of 6 weeks for the first reminder and a subsequent 4 weeks for the second reminder. Nonrespondents were excluded from the study after the second reminder. None of the respondents were compensated for their involvement, and all responses were voluntary. The anonymity of the respondents was maintained by processing the answers in a de-identified manner. As per the inclusion criteria, physiotherapists who are currently working in ICUs of various hospitals of Nepal were requested to fill the questionnaire. Physiotherapists with the qualification of Certificate in Physiotherapy (CPT), Bachelor of Physiotherapy (BPT), or Master of Physiotherapy (MPT) were included. The survey required about $15 \mathrm{~min}$ to complete and included questions regarding general information about the demographics of the primary hospital of employment and issues regarding PT staffing.

The survey also consisted of questions concerning a series of six scenarios of mechanically ventilated patients commonly encountered in the ICU. The physiotherapists were questioned regarding of the likelihood that PT would be consulted and the number of days per week that PT would be administered for each scenario. The likelihood that PT would be involved was considered to be "frequent" if the chosen percentage of involvement was $>75 \%$. Using a $1-7$ scale (where 1 was "very 
unlikely" and 7 was "very likely"), the physiotherapists were asked to determine the likelihood that six different types of PT would be performed for each of the six patient scenarios including chest PT (as defined by a regimen of postural drainage and chest manipulation), passive range of motion (ROM) exercises, positioning to prevent contractures and wounds, therapeutic exercise (as defined by either aerobic or resistive movement initiated by the patient with the assistance of the physiotherapist), functional mobility retraining (as defined by bed mobility, balance training, transfer training, and ambulation exercises), and functional electrical stimulation (FES). The final question for each of the six patient scenarios determined which single type of PT was felt to be the most efficacious for that patient scenario. ${ }^{[8]}$

\section{Statistical methods}

Data were first entered in Microsoft Excel ${ }^{\mathrm{TM}} 2010$ and then converted to Statistical Package for Social Sciences version 19.0 (IBM Corp., New York, USA). Data were summarized using descriptive statistics which were reported as mean \pm standard deviation (SD) or percentages. The Likert scores were summarized for each clinical scenario and each treatment modality as mean $\pm \mathrm{SD}$. Chi-square test was performed to calculate the likelihood of PT according to the six clinical scenarios. The ANOVA test was used to analyze the difference in treatment choices among the clinical scenarios, categorized as neurological (cerebrovascular accident [CVA] and C6 fracture), medical (chronic obstructive pulmonary disease [COPD] exacerbation, sepsis and pneumonia, myocardial infarction), and trauma (motor vehicle accident [MVA]). A $P>0.05$ was considered statistically significant at $95 \%$ confidence interval.

\section{Results}

The questionnaire was sent to 86 physiotherapists. From January 2014 to March 2015, a total of 52 physiotherapists representing hospitals from government, semi-government, and nongovernment hospitals responded to the survey (overall response rate of $60 \%$ ). Of these 63 respondents, there were 11 physiotherapists who declined participation in the survey citing reason that they no longer work in the ICU. The remaining 23 did not respond to the survey request even after sending reminder E-mails and phone calls. Therefore, the responses from 52 physiotherapists were included in the final analysis. A total of $25 \%(n=13)$ of the respondents worked in government hospital, $19.2 \%(n=10)$ in semi-government hospital, with the remaining $55.8 \%(n=29)$ working in private hospitals.
There were $61.5 \%$ of hospitals with $>10$ ICU beds, $36.5 \%$ with 10-20 ICU beds, and only $2 \%$ with more than 20 ICU beds. Among the respondent physiotherapists, qualification-wise, the majority have BPT (53.8\%), followed by MPT (25.0\%), or CPT (21.2\%). In the majority of hospitals (68.0\%), PT service was provided for ICU patients only after a physician consultation. Established hospital criteria for the initiation of PT in the ICU were present at $13.0 \%$ of the hospitals while, in $7 \%$ of the ICUs, all the cases were automatically evaluated by the physiotherapists, and 12\% of ICUs had dual system of physician referral and automatic evaluation of all cases in ICU by physiotherapists. Private hospitals were providing PT service more during weekends compared to government hospitals $(57.1 \%$ vs. $32.1 \% ; P=0.17)$. Most of the physiotherapists $(75.0 \%)$ worked in the ICU for 1-3 $\mathrm{h}$ per day only. It was likely that PT was routinely provided in all six of the patient scenarios. The likelihood of routine PT involvement varied significantly with the clinical scenario (highest $71.2 \%$ CVA, lowest 3.8\% myocardial infarction, $P<0.001)$ [Table 1].

With regard to the routine involvement of PT in treatment in all types of clinical scenario, it was found that in semi-government hospital, $46.7 \%$ of the physiotherapists were involved in routine care in more than $75 \%$ of the cases in ICU, followed by private hospital (37.4\%) and government hospital (30.8\%).

The most common and preferred types of PT treatments that were performed with these critically ill patients (irrespective of clinical scenarios) were chest PT (53.8\%) and positioning (for nonrespiratory reasons) $(21.2 \%)$ while the least utilized was therapeutic exercise $(3.8 \%)$.

The mean \pm SD Likert value for each PT technique according to clinical scenario showed the highest Likert score was for chest PT in four of the scenario, except in C6 fracture and MVA where positioning was scored highest, $6.35 \pm 0.95$ and $4.60 \pm 1.81$, respectively [Table 2].

\begin{tabular}{|c|c|c|}
\hline \multirow{2}{*}{$\begin{array}{l}\text { Clinical } \\
\text { scenario }\end{array}$} & \multicolumn{2}{|c|}{ Likelihood to care* $n(\%)$} \\
\hline & $<75 \%$ of the time & $>75 \%$ of the time \\
\hline CVA & $15(28.8)$ & $37(7 I .2)$ \\
\hline COPD & $44(84.6)$ & $8(I 5.4)$ \\
\hline C6 fracture & 21 (40.4) & $31(59.6)$ \\
\hline MI & $50(96.2)$ & $2(3.8)$ \\
\hline Pneumonia & $48(92.3)$ & $4(7.7)$ \\
\hline MVA & $17(32.7)$ & $35(67.3)$ \\
\hline Total & $195(62.5)$ & $117(37.5)$ \\
\hline
\end{tabular}




\begin{tabular}{|c|c|c|c|c|c|c|}
\hline & $\begin{array}{c}\text { Chest } \\
\text { physiotherapy }\end{array}$ & $\begin{array}{l}\text { Passive } \\
\text { ROM }\end{array}$ & Positioning & $\begin{array}{l}\text { Therapeutic exercises } \\
\text { (aerobic or resistive) }\end{array}$ & $\begin{array}{l}\text { Functional mobility } \\
\text { retraining }\end{array}$ & $\begin{array}{c}\text { Functional electrical } \\
\text { stimulation }\end{array}$ \\
\hline \multicolumn{7}{|l|}{ Neurological } \\
\hline CVA & $6.00 \pm 1.10$ & $5.31 \pm 1.69$ & $5.60 \pm 1.39$ & $3.58 \pm 1.67$ & $3.96 \pm 1.86$ & $2.33 \pm 1.26$ \\
\hline C6 fracture & $5.79 \pm 1.19$ & $6.15 \pm 1.14$ & $6.35 \pm 0.95$ & $3.46 \pm 1.84$ & $3.81 \pm 2.03$ & $3.06 \pm 1.65$ \\
\hline \multicolumn{7}{|l|}{ Trauma } \\
\hline MVA with liver laceration & $4.40 \pm 1.91$ & $3.73 \pm 1.90$ & $4.60 \pm 1.81$ & $3.35 \pm 1.75$ & $3.17 \pm 1.92$ & $1.50 \pm 0.96$ \\
\hline \multicolumn{7}{|l|}{ Medical } \\
\hline COPD exacerbation & $6.02 \pm 1.43$ & $3.38 \pm 1.76$ & $4.52 \pm 1.74$ & $3.87 \pm 1.72$ & $3.73 \pm 1.86$ & $1.50 \pm 0.87$ \\
\hline Sepsis and pneumonia & $5.7 I \pm I .66$ & $2.98 \pm I .8 I$ & $4.40 \pm 1.79$ & $4.02 \pm 1.84$ & $2.90 \pm 1.49$ & $1.46 \pm 0.90$ \\
\hline MI & $5.04 \pm 1.57$ & $3.10 \pm 1.74$ & $3.69 \pm 2.09$ & $3.67 \pm 1.77$ & $3.65 \pm 1.79$ & $1.44 \pm 0.87$ \\
\hline
\end{tabular}

The values are mean \pm SD of a Likert score (from I (very unlikely) to 7 (very likely)). ROM: Range of motion; CVA: Cerebrovascular accident; MVA: Motor vehicle accident; COPD: Chronic obstructive pulmonary disease; MI: Myocardial infarction; SD: Standard deviation

The least Likert score was for electrical stimulation in all clinical scenarios, with a mean \pm SD Likert value of $1.88 \pm 1.27$ across all clinical scenarios.

To analyze the difference in treatment choices among the clinical scenarios, they were categorized as neurological (CVA and C6 fracture), medical (COPD exacerbation, sepsis and pneumonia, myocardial infarction), and trauma (MVA). The ANOVA test results showed that there was a significant difference in likelihood of use of the treatment options such as chest PT, passive ROM, positioning, functional mobility training, and electrical stimulation among the different clinical scenarios. However, therapeutic exercises (aerobic or resistive) were provided to all patients irrespective of clinical scenarios $(P=0.125)$ [Table 3].

\section{Discussion}

Recently, there have been few reviews about role of physiotherapists, ${ }^{[12-16]}$ but sufficient evidence-based practice guidelines are still lacking with specific scope of practice for physiotherapists in ICU. Literature regarding the staffing levels and availability of physiotherapists in the ICU is even rarer.

In this Nepalese survey, several important trends were identified concerning the utilization of PT for critically ill patients. In the majority of hospitals (68\%), PT service was initiated for ICU patients only after a physician consultation, which is similar to the USA ${ }^{[8]}$ The majority of physiotherapists $(73.2 \%)$ required neurologists/ neurosurgeon's referral to treat the neurological ICU patients in India. ${ }^{[17]}$ In $13.0 \%$ of the hospitals in Nepal, all the cases in ICU were evaluated by physiotherapist automatically under "blanket referral" provisions. In this study, there were $7 \%$ hospitals which had established criteria for the initiation of PT for ICU patients, which is similar to the USA ( $>10 \%$ of hospitals) $\cdot{ }^{[8]}$
Table 3: Effect of patient scenario on the likelihood of using different types of physiotherapy treatment

\begin{tabular}{|c|c|c|c|}
\hline & $n$ & Mean \pm SD $^{a}$ & $P$ \\
\hline \multicolumn{4}{|c|}{ Chest physiotherapy } \\
\hline Neurological & 104 & $5.89 \pm 1.1$ & 0.000 \\
\hline Medical & 156 & $5.59 \pm 1.6$ & \\
\hline Trauma & 52 & $4.60 \pm 1.9$ & \\
\hline \multicolumn{4}{|l|}{ Passive ROM } \\
\hline Neurological & 104 & $5.73 \pm 1.5$ & 0.000 \\
\hline Medical & 156 & $3.15 \pm 1.8$ & \\
\hline Trauma & 52 & $3.73 \pm 1.9$ & \\
\hline \multicolumn{4}{|l|}{ Positioning } \\
\hline Neurological & 104 & $5.97 \pm 1.2$ & $0.000^{\mathrm{b}}$ \\
\hline Medical & 156 & $4.21 \pm 1.9$ & \\
\hline Trauma & 52 & $4.40 \pm 1.8$ & \\
\hline \multicolumn{4}{|c|}{ Therapeutic exercises (aerobic or resistive) } \\
\hline Neurological & 104 & $3.52 \pm 1.7$ & 0.125 \\
\hline Medical & 156 & $3.85 \pm 1.8$ & \\
\hline Trauma & 52 & $3.35 \pm 1.7$ & \\
\hline \multicolumn{4}{|c|}{ Functional mobility retraining } \\
\hline Neurological & 104 & $3.88 \pm 1.9$ & 0.045 \\
\hline Medical & 156 & $3.43 \pm 1.7$ & \\
\hline Trauma & 52 & $3.17 \pm 1.9$ & \\
\hline \multicolumn{4}{|c|}{ Functional electrical stimulation } \\
\hline Neurological & 104 & $2.69 \pm 1.5$ & $0.000^{\mathrm{b}}$ \\
\hline Medical & 156 & $1.47 \pm 0.9$ & \\
\hline Trauma & 52 & $1.50 \pm 0.9$ & \\
\hline
\end{tabular}

ANOVA test $\left({ }^{b} P<0.00 I\right)$ performed to analyze the difference in treatment choices among the clinical scenarios, categorized as neurological (CVA and C6 fracture), medical (COPD exacerbation, sepsis and pneumonia, MI) and trauma (MVA); ${ }^{\mathrm{T}}$ The values are mean \pm SD of Likert score (from I (very unlikely) to 7 (very likely)). ROM: Range of motion; CVA: Cerebrovascular accident; MVA: Motor vehicle accident; COPD: Chronic obstructive pulmonary disease; SD: Standard deviation; MI: Myocardial infarction

The availability of physiotherapist on all 7 days of a week was $55.8 \%$ in private hospital and only $25 \%$ in government hospitals. The low availability shows that the need and importance of regular PT in the ICU is still not clearly recognized across Nepal. A study from Australia reported the availability of physiotherapists over the weekend was $66 \%{ }^{[18]}$ In the USA, $58 \%$ of the university hospitals and $68 \%$ of the community hospitals had routine weekend physiotherapist coverage ${ }^{\left[{ }^{8]}\right.}$ In this study, consistent with the study done in the USA, the likelihood that a patient received PT varied significantly with the type of hospital. ${ }^{[8]}$ 
Stiller in her review of the evidence for ICU PT practice suggested that positioning, mobilization, manual hyperinflation, percussions and vibrations, suctioning, exercises, and continuous rotational therapy were the main roles fulfilled by the ICU physiotherapist. ${ }^{[1,5,10,16]}$ In this study, consistent with results from the USA, the likelihood that a patient received $\mathrm{PT}$ varied significantly with the specific clinical scenario. ${ }^{[8]}$ In this study, the most preferred PT treatment is chest PT, followed by positioning. Similar to European, Indian, and Australian contexts, physiotherapists in Nepal were likely to provide chest PT to critically ill patients. ${ }^{[18-20]}$ In a study done in Australia, when asked whether patients received routine chest PT, 55\% stated every 4 h. ${ }^{[18]}$ The efficacy of "chest PT," defined variously as combinations of positioning, manual hyperinflation and percussion and vibrations, on short-term patient physiological outcomes has been studied extensively. ${ }^{[21-25]}$ There is moderate-to-strong evidence to suggest that PT treatment is effective in recruiting alveoli, ${ }^{[24,26]}$ improving secretion clearance, ${ }^{[21,22]}$ compliance, ${ }^{[21,22,27]}$ airway resistance, ${ }^{[28]}$ gas exchange, ${ }^{[29]}$ and reducing the incidence of ventilator acquired pneumonia. ${ }^{[30]}$

In regard to positioning, a study done by Thomas et al. in Australia showed that the practice of positioning was reported to occur in $47 \%$ of the cases. ${ }^{[31]}$ A study demonstrated that a high percentage (83\%) of physiotherapists agree that rationales for positioning are associated with preventing pressure necrosis and improving patient comfort. ${ }^{[31]}$ A survey by King and Crowe demonstrated nurses and physicians rated pressure ulceration prevention as the primary aim of positioning, followed by matching ventilation and perfusion. ${ }^{[32]}$

In this study, the least preferred form of treatment is therapeutic exercise; this contrasts with the USA, where the most common PT interventions in ICU were functional mobility retraining and therapeutic exercises. ${ }^{[8]}$ In Nepal, there is a significant variability among the physiotherapists as to the choice of therapeutic exercise according to the clinical scenarios $(P=0.125)$; in addition, therapeutic exercise is the least common form of PT treatment in Nepal, which could be due to lack of awareness among Nepali physiotherapists. In a study done by Skinner et al., $42 \%$ physiotherapists felt that exercise was indicated in all ICU patients, ${ }^{[33]}$ where active-assisted/free active exercise was the most common form of exercise prescribed. The aim of therapeutic exercise is to maintain or restore strength, flexibility, and endurance. In therapeutic exercise sessions, the patient may undergo exercises aimed at passively and actively training both the lower and upper extremities, such as lifting light weights or pushing against resistance ${ }^{[8]}$ In a developing country as Nepal, where in the capital city's hospitals, there is availability of invasive blood pressure monitoring devices only in $50 \%$ of the ICUs; ${ }^{[34]}$ it is obvious that there are lesser chances of availability of resistance training devices such as leg press and dumbbells. With the lack of proper devices and less awareness about its importance, the physiotherapists are not able to provide required therapeutic exercises.

In this study, FES was the least selected intervention across all clinical scenarios. Adding FES to usual care proved to be more effective than usual care alone for preventing skeletal muscle weakness in critically ill patients ${ }^{[35]}$ and also results in shorter duration of weaning. ${ }^{[36]}$ Neuromuscular electrical stimulation was associated with an increase in strength of the stimulated muscle in septic patients requiring mechanical ventilation. ${ }^{[37]}$ However, there is still inconclusive evidence for its benefit in prevention of muscle wasting.

There are several limitations of our study. The response rate to the survey was only $60 \%$, which could be due to lack of availability of internet facility. The respondents could have provided a completely different view than actual practice since we used self-reported survey with Likert-style response set, which made the study vulnerable to response bias. The maximum of the nonrespondents were from the hospitals outside of the capital of Nepal, so the practice pattern in all the parts of country may not have been identified. In addition, the survey used questionnaire adopted from a previous study in the USA, which collected the opinion of the physiotherapist concerning common but hypothetical patient scenarios, rather than collecting actual from the hospitals data about such practices. The questionnaire was developed in USA where there is more number of respiratory therapists (who have more exposure to ICU practice) than physiotherapists in ICUs whereas, in Nepal, there are only physiotherapists. The opinions of other health care professionals, such as nursing and critical care physicians, were also not included in this survey to determine their activities with ICU patients. Hence, in future, the survey should be based more on collection of common practices and inclusion of multidisciplinary health professional opinion to PT practices to get a better understanding. 


\section{Conclusion}

The involvement of physiotherapists in ICUs of Nepal is lesser than compared to the developed countries. There is a lack of regular service of PT on weekends in the ICUs of Nepal and lesser hours are spent in ICU. Most of the cases in ICUs are treated by physiotherapists only after physician's referral. Moreover, the preferred intervention seems to be limited only to chest PT. The physiotherapists in ICUs of Nepal are still not practicing therapeutic exercise and functional mobility training to a great extent, which has more growing evidence of effectiveness for ICU survivors.

\section{Acknowledgment}

The authors would like to acknowledge Nepal Health Professional Council for providing the list of registered physiotherapists in Nepal. The authors would also like to acknowledge the Ministry of Health, Nepal, for providing the official list of registered hospitals of Nepal. We would also like to thank all physiotherapists for giving their valuable time to participate in the survey.

\section{Financial support and sponsorship Nil.}

\section{Conflicts of interest}

There are no conflicts of interest.

\section{References}

1. Gosselink R, Bott J, Johnson M, Dean E, Nava S, Norrenberg M, et al. Physiotherapy for adult patients with critical illness: Recommendations of the European respiratory society and European society of intensive care medicine task force on physiotherapy for critically ill patients. Intensive Care Med 2008;34:1188-99.

2. Gosselink R, Clerckx B, Robbeets C, Vanhullebusch T, Vanpee G, Segers J. Physiotherapy in the intensive care unit. Neth J Crit Care 2011;15:66-75.

3. Moseley AM, Herbert RD, Sherrington C, Maher CG. Evidence for physiotherapy practice: A survey of the physiotherapy evidence database (PEDro). Aust J Physiother 2002;48:43-9.

4. Stiller K. Physiotherapy in intensive care: Towards an evidence-based practice. Chest 2000;118:1801-13.

5. Stiller K. Physiotherapy in intensive care: An updated systematic review. Chest 2013;144:825-47.

6. Schweickert WD, Kress JP. Implementing early mobilization interventions in mechanically ventilated patients in the ICU. Chest 2011;140:1612-7.

7. Thomas AJ. Physiotherapy led early rehabilitation of the patient with critical illness. Phys Ther Rev 2011;16:46-57.

8. Hodgin KE, Nordon-Craft A, McFann KK, Mealer ML, Moss M. Physical therapy utilization in intensive care units: Results from a national survey. Crit Care Med 2009;37:561-6.

9. Lunardi N, Bryant M, Smith K, Lowson S. Early mobilization in critically ill patients. ICU Dir 2012;3:17-20.

10. Hodgson CL, Stiller K, Needham DM, Tipping CJ, Harrold M, Baldwin CE, et al. Expert consensus and recommendations on safety criteria for active mobilization of mechanically ventilated critically ill adults. Crit Care 2014 4;18:658.

11. Owoeye IO. The Advances of Physiotherapy: University of Lagos; 2002. Available from: http://www.nuc.edu.ng/nucsite/File/ILS\%202002/ ILS-87.pdf. [Last accessed 2015 Jul 09].

12. Nydahl P, Ruhl AP, Bartoszek G, Dubb R, Filipovic S, Flohr HJ, et al. Early mobilization of mechanically ventilated patients: A 1-day point-prevalence study in Germany. Crit Care Med 2014;42:1178-86.

13. Berney SC, Harrold M, Webb SA, Seppelt I, Patman S, Thomas PJ, et al. Intensive care unit mobility practices in Australia and New Zealand: A point prevalence study. Crit Care Resusc 2013;15:260-5.

14. Li Z, Peng X, Zhu B, Zhang Y, Xi X. Active mobilization for mechanically ventilated patients: A systematic review. Arch Phys Med Rehabil 2013;94:551-61.

15. Adler J, Malone D. Early mobilization in the intensive care unit: A systematic review. Cardiopulm Phys Ther J 2012;23:5-13.

16. Kayambu G, Boots R, Paratz J. Physical therapy for the critically ill in the ICU: A systematic review and meta-analysis. Crit Care Med 2013;41:1543-54.

17. Bhat A, Chakravarthy K, Rao BK. Chest physiotherapy techniques in neurological intensive care units of India: A survey. Indian J Crit Care Med 2014;18:363-8.

18. Chaboyer W, Gass E, Foster M. Patterns of chest physiotherapy in Australian Intensive Care Units. J Crit Care 2004;19:145-51.

19. Norrenberg M, Vincent JL. A profile of European intensive care unit physiotherapists. European society of intensive care medicine. Intensive Care Med 2000;26:988-94.

20. Kumar JA, Maiya AG, Pereira D. Role of physiotherapists in intensive care units of India: A multicenter survey. Indian J Crit Care Med 2007;11:198-203.

21. Berney S, Denehy L, Pretto J. Head-down tilt and manual hyperinflation enhance sputum clearance in patients who are intubated and ventilated. Aust J Physiother 2004;50:9-14.

22. Hodgson C, Denehy L, Ntoumenopoulos G, Santamaria J, Carroll S. An investigation of the early effects of manual lung hyperinflation in critically ill patients. Anaesth Intensive Care 2000;28:255-61.

23. Jones AY, Hutchinson RC, Oh TE. Effects of bagging and percussion on total static compliance of the respiratory system. Physiotherapy 1992;78:661-6.

24. Maa SH, Hung T.J, Hsu KH, Hsieh YI, Wang KY, Wang CH, et al. Manual hyperinflation improves alveolar recruitment in difficult-to-wean patients. Chest 2005;128:2714-21.

25. Ntoumenopoulos G, Gild A, Cooper DJ. The effect of manual lung hyperinflation and postural drainage on pulmonary complications in mechanically ventilated trauma patients. Anaesth Intensive Care 1998;26:492-6.

26. Stiller K, Geake T, Taylor J, Grant R, Hall B. Acute lobar atelectasis. A comparison of two chest physiotherapy regimens. Chest 1990;98:1336-40.

27. Berney S, Denehy L. A comparison of the effects of manual and ventilator hyperinflation on static lung compliance and sputum production in intubated and ventilated intensive care patients. Physiother Res Int 2002;7:100-8.

28. Choi JS, Jones AY. Effects of manual hyperinflation and suctioning in respiratory mechanics in mechanically ventilated patients with ventilator-associated pneumonia. Aust J Physiother 2005;51:25-30.

29. Patman S, Jenkins S, Stiller K. Manual hyperinflation - Effects on respiratory parameters. Physiother Res Int 2000;5:157-71.

30. Ntoumenopoulos G, Presneill JJ, McElholum M, Cade JF. Chest physiotherapy for the prevention of ventilator-associated pneumonia. Intensive Care Med 2002;28:850-6.

31. Thomas PJ, Paratz JD, Stanton WR, Deans R, Lipman J. Positioning practices for ventilated intensive care patients: Current practice, indications and contraindications. Aust Crit Care 2006;19:122-6, 128, $130-2$.

32. King J, Crowe J. Mobilization practices in Canadian critical care units. Physiother Can 1998;50:206-11. 
33. Skinner EH, Berney S, Warrillow S, Denehy L. Rehabilitation and exercise prescription in Australian intensive care units. Physiotherapy 2008;94:220-9.

34. Shrestha R, Bajracharya PV. A survey of adult intensive care units in Kathmandu valley. Postgrad Med J NAMS 2011;11:1-7.

35. Maffiuletti NA, Roig M, Karatzanos E, Nanas S. Neuromuscular electrical stimulation for preventing skeletal-muscle weakness and wasting in critically ill patients: A systematic review. BMC Med 2013;11:137.
36. Routsi C, Gerovasili V, Vasileiadis I, Karatzanos E, Pitsolis T, Tripodaki E, et al. Electrical muscle stimulation prevents critical illness polyneuromyopathy: A randomized parallel intervention trial. Crit Care 2010;14:R74.

37. Rodriguez PO, Setten M, Maskin LP, Bonelli I, Vidomlansky SR, Attie S, et al. Muscle weakness in septic patients requiring mechanical ventilation: Protective effect of transcutaneous neuromuscular electrical stimulation. J Crit Care 2012;27:319.e1-8. 